\title{
Menopausal hormone therapy and breast cancer: what is the true size of the increased risk?
}

Michael E Jones ${ }^{*},{ }^{1}$, Minouk J Schoemaker ${ }^{1}$, Lauren Wright ${ }^{1}$, Emily McFadden ${ }^{1,6}$, James Griffin ${ }^{1,7}$, Dawn Thomas ${ }^{1}$, Jane Hemming ${ }^{1}$, Karen Wright ${ }^{2}$, Alan Ashworth ${ }^{3,4,5,8}$ and Anthony J Swerdlow ${ }^{1,3}$

${ }^{1}$ Division of Genetics and Epidemiology, The Institute of Cancer Research, London SW7 3RP, UK; ${ }^{2}$ The National Cancer Registration Service-Eastern Office, Public Health England, Cambridge CB21 5XA, UK; ${ }^{3}$ Division of Breast Cancer Research, The Institute of Cancer Research, London SW7 3RP, UK; ${ }^{4}$ Breakthrough Breast Cancer Research Centre at The Institute of Cancer Research, London SW7 3RP, UK and ${ }^{5}$ Division of Molecular Pathology, The Institute of Cancer Research, London SW7 3RP, UK

Background: Menopausal hormone therapy (MHT) increases breast cancer risk; however, most cohort studies omit MHT use after enrolment and many infer menopausal age.

Methods: We used information from serial questionnaires from the UK Generations Study cohort to estimate hazard ratios (HRs) for breast cancer among post-menopausal women with known menopausal age, and examined biases induced when not updating data on MHT use and including women with inferred menopausal age.

Results: Among women recruited in 2003-2009, at 6 years of follow-up, 58148 had reached menopause and $96 \%$ had completed a follow-up questionnaire. Among 39183 women with known menopausal age, 775 developed breast cancer, and the HR in relation to current oestrogen plus progestogen MHT use (based on 52 current oestrogen plus progestogen MHT users in breast cancer cases) relative to those with no previous MHT use was 2.74 (95\% confidence interval (CI): 2.05-3.65) for a median duration of 5.4 years of current use, reaching 3.27 ( $95 \% \mathrm{Cl}: 1.53-6.99$ ) at 15 + years of use. The excess HR was underestimated by $53 \%$ if oestrogen plus progestogen $\mathrm{MHT}$ use was not updated after recruitment, $13 \%$ if women with uncertain menopausal age were included, and $59 \%$ if both applied. The HR for oestrogen-only MHT was not increased (HR=1.00; 95\% Cl: 0.66-1.54).

Conclusions: Lack of updating MHT status through follow-up and inclusion of women with inferred menopausal age is likely to result in substantial underestimation of the excess relative risks for oestrogen plus progestogen MHT use in studies with long follow-up, limited updating of exposures, and changing or short durations of use.

Menopausal hormone therapy (MHT) provides effective relief from climacteric symptoms but some are associated with increased risk of stroke, venous thromboembolism, and breast, ovarian, and endometrial cancers (Medicines and Healthcare Products Regulatory Agency UK, 2007; Santen et al, 2010). The MHT prescribing decreased rapidly (Ameye et al, 2014) after its adverse effects on risk of breast cancer were highlighted in reports from the Women's Health Initiative trial (Rossouw et al, 2002) and the Million Women Study (Beral and Million Women Study Collaborators, 2003), but nevertheless it continues to be used by many women worldwide (Chlebowski and Anderson, 2012; Antoine et al, 2016).

*Correspondence: Dr ME Jones; E-mail: Michael.Jones@icr.ac.uk

${ }^{6}$ Current address: Nuffield Department of Primary Care Health Sciences, University of Oxford, Oxford, OX2 6GG, UK.

${ }^{7}$ Current address: Warwick Clinical Trials Unit, Division of Health Sciences, Warwick Medical School, The University of Warwick, Coventry, CV4 7AL, UK.

${ }^{8}$ Current address: UCSF Helen Diller Family Comprehensive Cancer Center, San Francisco, CA 94158, USA.

Received 6 April 2016; revised 30 June 2016; accepted 6 July 2016; published online 28 July 2016

(c) 2016 Cancer Research UK. All rights reserved 0007-0920/16

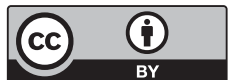


Accurate information about the risks (and benefits) of MHT is essential to allow women to make informed decisions about their health, and evidence from observational studies is important because it is no longer justifiable to conduct long-term trials of MHT safety (Vickers et al, 2007). There are, however, shortfalls in the way information has been collected and analysed in most published epidemiological studies (Colditz et al, 1995; Magnusson et al, 1999; Li et al, 2000; Schairer et al, 2000; Daling et al, 2002; Newcomb et al, 2002; Beral and Million Women Study Collaborators, 2003; Li et al, 2003; Bakken et al, 2004, 2011; Chen et al, 2004, 2006; Stahlberg et al, 2004; Fournier et al, 2005; Brinton et al, 2008; Saxena et al, 2010; Beral et al, 2011; Calvocoressi et al, 2012; Ritte et al, 2012; Cordina-Duverger et al, 2013; Nyante et al, 2013; Fournier et al, 2014; Thorbjarnardottir et al, 2014; Roman et al, 2016). In prospective studies that only collect information on MHT up to the time of recruitment (e.g., cohort studies with no follow-up questionnaires) current use of MHT and duration of use may be misclassified because some never users of MHT will become users during follow-up, and some users will become ex-users; this may lead to biased assessment of breast cancer risk in relation to MHT use (Van Leeuwen and Rookus, 2003; Lee et al, 2005) but the extent has not been assessed empirically. In addition, analyses that include women who have had simple hysterectomy (i.e., without oophorectomy) before natural menopause will also lead to biased results (Collaborative Group on Hormonal Factors in Breast Cancer, 1997; Pike et al, 1998; Rockhill et al, 2000; Simpson et al, 2007) but many case-control and cohort studies include such women (Colditz et al, 1995; Magnusson et al, 1999; Li et al, 2000; Schairer et al, 2000; Daling et al, 2002; Newcomb et al, 2002; Beral and Million Women Study Collaborators, 2003; Li et al, 2003; Bakken et al, 2004, 2011; Chen et al, 2004, 2006; Stahlberg et al, 2004; Fournier et al, 2005; Brinton et al, 2008; Saxena et al, 2010; Beral et al, 2011; Calvocoressi et al, 2012; Ritte et al, 2012; CordinaDuverger et al, 2013; Fournier et al, 2014; Thorbjarnardottir et al, 2014; Roman et al, 2016). Thus, although the epidemiological evidence clearly shows an increased risk of breast cancer with MHT use (Campagnoli et al, 2005; Greiser et al, 2005; Lee et al, 2005), there is uncertainty about the magnitude of the risk.

To address these issues we used serial questionnaire information from the Breakthrough Generations Study (BGS), which has ascertained MHT use and menopausal status at entry and during prospective follow-up, to estimate the relative risk of breast cancer in relation to MHT use among women whose age at menopause was known. We also assessed the likely extent of the biases that occur when only baseline questionnaire information is available and if women with simple hysterectomy are included in analyses.

\section{MATERIALS AND METHODS}

The BGS is a cohort study of 113693 women from the United Kingdom, aged $\geqslant 16$ years, from whom questionnaire information and informed consent was gained at recruitment during 20032015. The first follow-up questionnaire was completed at 2.5 years after recruitment, a second at $\sim 6$ years, and a third at 9.5 years. The study was approved by the South East Multi-Centre Research Ethics Committee.

Breast and other cancers occurring in the cohort were identified from recruitment and follow-up questionnaires and spontaneous reports to the study centre. Confirmation of diagnosis was obtained from the cancer registries in the United Kingdom, 'flagging' at the National Health Service Central Registers (virtually complete registers of the populations of England and Wales, and of Scotland, to which study participants can be linked and on which deaths and cancer registrations are 'flagged' and then periodically reported to authorised medical researchers), pathology reports, and correspondence with patients' general practitioners.

Information on MHT was obtained at recruitment and from the second follow-up questionnaire, and was used to assess MHT exposure from menopause to date of breast cancer incidence or end of follow-up. Women were asked the ages or years they started and stopped episodes of MHT use, whether they were still using MHT, and the name of each drug used. We also asked participants at recruitment and in the second follow-up questionnaire how old they were when their periods stopped completely (i.e., they had gone 6 months without having had a period). Women who could not report age at natural menopause, because of hysterectomy without bilateral oophorectomy or because they were taking MHT or oral contraceptives around the time of menopause (i.e., at least 6 months without having a period and not being pregnant), were excluded from the main analyses because it was not possible to determine the age at which their ovarian function ceased. Information was also collected on other breast cancer risk factors (Swerdlow et al, 2011).

Statistical analysis. The current analytic cohort is based on all women who were recruited to the study during June 2003 to December 2009 inclusive without previous breast cancer. The recruitment cutoff at December 2009 was selected because at the time of analysis the follow-up for the second questionnaire was practically complete for this group of recruits. Women with known age at menopause entered risk at their date of recruitment or menopause, whichever was later, and were censored at the earliest date of: first invasive or in situ breast cancer, death, follow-up questionnaire, or loss to study follow-up. Left-truncated and rightcensored Cox proportional hazards regression (Cox, 1972) using attained age as the implicit timescale was used to estimate hazard ratios (HRs) and 95\% confidence intervals (CIs) for MHT use and risk of first invasive or in situ breast cancer, adjusted for (continuous) menopausal age.

The MHT was analysed as a time-varying exposure lagged by 1 year (Schairer et al, 2000; Fournier et al, 2005). The effect of the lag was to make the year following start of treatment a nonexposed period (as the exposure within the early months of use is unlikely to be the cause of breast cancers occurring in that period), and the year after cessation to be considered a part of the period of exposure; this avoided a potential 'reverse causation' bias, as MHT may be stopped during work-up to a formal breast cancer diagnosis. Follow-up time for each woman was divided into the period(s), after onset of menopause, that were: before MHT use, current MHT use, and after cessation of MHT use. A woman could move from being a user to ex-user to user again if there was a gap of at least 1 year between periods of MHT use (reports of MHT ending and re-starting within 1 year were treated as contiguous periods of use). In sensitivity analyses exploring the effect of not updating MHT use beyond baseline we assumed a duration of use as recorded at baseline and did not extrapolate the duration of use beyond that reported at baseline.

Drug preparation was assigned based on the type of MHT used longest during each contiguous episode of use. Tests for trend in duration of current use were calculated over periods of $0-<1,1-$ $<2, \ldots$ years, scored as $0.5,1.5, \ldots$, and included an indicator variable for current user $v s$ never user (i.e., never users were not treated as users with zero duration but as a separate category to allow for systematic differences between those who are prescribed MHT and those who are not). Heterogeneity in HRs for subtypes of breast cancer by behaviour, oestrogen receptor status, and morphology was assessed using a data augmentation method (Lunn and McNeil, 1995). To assess potential confounding in addition to that due to age at menopause (as a continuous variable) we also adjusted for: birth cohort, benign breast disease, family history of breast cancer in first-degree relatives, socioeconomic score, age at 
menarche, age at first pregnancy and parity, duration of breastfeeding, oral contraceptive use before menopause, alcohol consumption, physical activity, pre-menopausal body mass index (BMI) at age 20 years, and post-menopausal BMI at recruitment (or if unavailable, from second follow-up questionnaire). We included any breast cancers diagnosed after recruitment (i.e., no minimum interval) but adjusted for, and tested for heterogeneity in, time since recruitment to BGS cohort ( $<1$ year; $1+$ year). We carried out additional analyses including women with uncertain menopausal age by including follow-up from these women only from age 58 years (the age by which $99 \%$ of women with known menopausal age were post-menopausal) but, to allow adjustment for menopausal age and estimation of duration of MHT use since menopause, we assumed menopause occurred at age 50 years (and only considered MHT use if it was used from this age). All statistical tests were two sided and analyses were conducted using Stata/IC version 14.0 (StataCorp, 2015).

\section{RESULTS}

During 2003-2009, a recruitment questionnaire was completed by 104164 women who joined the BGS without prior breast cancer (or mastectomy), of whom 58148 were established as postmenopausal before the censoring date for analysis. The first followup questionnaire at 2.5 years after recruitment was completed by 57592 of these women $(99.0 \%)$ and the second follow-up questionnaire at $\sim 6$ years after recruitment was completed by $55923(96.2 \%)$ of these post-menopausal women (3.7\% completed an abridged version by telephone). Of the remainder at second follow-up, $1.2 \%$ had died by this time, $1.7 \%$ were alive but had not completed the questionnaire although their vital and cancer status was available from 'flagging' at the National Health Service Central Registers, and $0.9 \%$ were lost to follow-up at an earlier date (e.g., emigrations) or no follow-up was available. The follow-up rate (calculated as the total observed person-years divided by the person-years that would have been achievable if all postmenopausal women were followed-up to their second questionnaire or, if earlier, death) was $99.5 \%$.

Menopausal age was known for 39183 women and was uncertain (i.e., by hysterectomy, MHT, or oral contraceptive use) for 18965 women. Of those with known menopausal age, 88.9\% reported a natural menopause and $9.4 \%$ reported bilateral oophorectomy as the reason for menopause; the remaining $1.7 \%$ reported various other procedures or treatments. The median interval between menopause and subsequent recruitment for the 30113 women known to be post-menopausal at recruitment was 7 years (interquartile range: 3 to 13 years). There were 9070 women pre-menopausal at recruitment who subsequently became postmenopausal during follow-up and at that point became eligible for analysis (median interval between recruitment and incident menopause for these 9070 women: 4 years; interquartile range: 2 to 5 years). The following results, unless otherwise stated, are based on the women with known menopausal age. The mean menopausal age was 50.2 (s.d.: 4.6) years and mean post-menopausal BMI was 25.7 (s.d.: 4.5) $\mathrm{kg} \mathrm{m}^{-2}$. Table 1 presents further descriptive characteristics of the cohort and the pattern of MHT use at recruitment: $5.0 \%$ of women who had not used MHT by recruitment subsequently used MHT sometime during follow-up and $65.4 \%$ of current users at recruitment ceased use by end of follow-up. At recruitment the median duration of use of oestrogenonly MHT was 6.5 years (interquartile range: 2.5 to 10.5 years), of oestrogen plus progestogen MHT was 5.5 years (interquartile range: 2.5 to 9.5 years), and was 4.5 .years (interquartile range: 1.5 to 8.5 years) for other types of MHT. Supplementary Table 1 describes the 775 first incident invasive or in situ breast cancers that were diagnosed during 204390 person-years (median 6.0
Table 1. Characteristics of women from the Breakthrough Generations Study who were recruited during 2003-2009 and became post-menopausal before end of follow-up

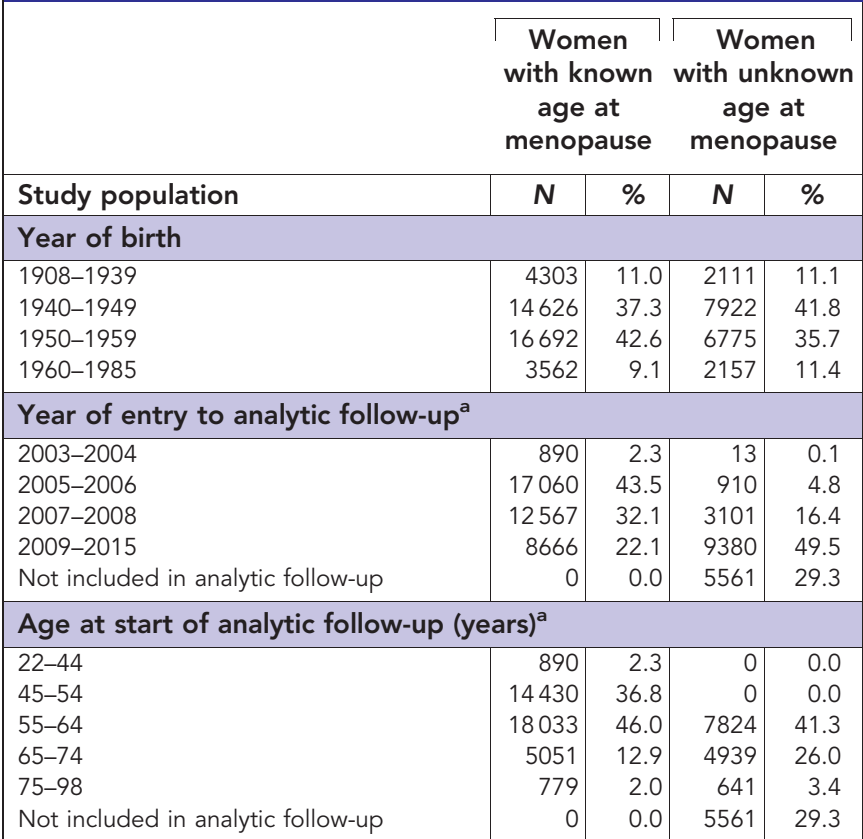

Family history of breast cancer in first-degree relative

\begin{tabular}{|l|l|l|l|l|}
\hline None reported & 32614 & 83.2 & 16019 & 84.5
\end{tabular}

\begin{tabular}{|l|r|r|r|r|} 
None reported & 32614 & 83.2 & 16019 & 84.5 \\
Yes & 6569 & 16.8 & 2946 & 15.5 \\
\hline
\end{tabular}

History of benign breast disease

\begin{tabular}{|l|l|l|l|l|}
\hline None reported & 29455 & 75.2 & 13752 & 72.5 \\
\hline
\end{tabular}

Yes

\begin{tabular}{|l|r|r|r|r|}
\hline Age at menarche (years) \\
\hline $7-11$ & 8091 & 20.7 & 4177 & 22.0 \\
$12-14$ & 23665 & 60.4 & 11122 & 58.6 \\
$15-19$ & 3806 & 9.7 & 1784 & 9.4 \\
Not known & 3621 & 9.2 & 1882 & 9.9 \\
\hline Parity & 5404 & 13.8 & 2110 & 11.1 \\
\hline Nulliparous & 33724 & 86.1 & 16825 & 88.7 \\
Parous & 55 & 0.1 & 30 & 0.2 \\
Not known & 7576 & 19.3 & 3385 & 17.9 \\
\hline Oral contraceptive use & 31607 & 80.7 & 15580 & 82.2 \\
\hline None reported &
\end{tabular}

Post-menopausal MHT use at recruitment ${ }^{\mathrm{b}}$

\begin{tabular}{|l|r|r|r|r|}
\hline No previous use & 20114 & 66.8 & 5414 & 36.2 \\
Ex-user & 5771 & 19.2 & 5495 & 36.7 \\
Current user: oestrogen only & 1719 & 5.7 & 1905 & 12.7 \\
Current user: oestrogen plus progestogen & 1612 & 5.4 & 1491 & 10.0 \\
Current user: other or unspecified MHT & 398 & 1.3 & 211 & 1.4 \\
Dates used unknown & 499 & 1.7 & 440 & 2.9
\end{tabular}

Total number of subjects

Abbreviation: $\mathrm{MHT}=$ menopausal hormone therapy

${ }^{\text {a }}$ Start of analytic follow-up based on latest of recruitment date or date became postmenopausal, or for women with unknown age at menopause, date became aged 58 years.

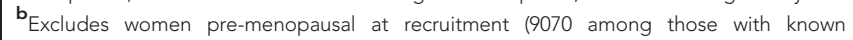
menopausal age; 4009 among those with unknown menopausal age).

years) of follow-up among 39183 women with known age at menopause (and similar descriptive statistics for 18965 women with unknown age at menopause).

The HR for invasive and in situ breast cancer adjusted for menopausal and attained age was 1.95 (95\% CI: 1.55-2.46; $P<0.001)$ for current users of all types of MHT relative to never users (Table 2). The HR increased with duration of current use by 
$3.8 \%$ per year (95\% CI: $0.4-7.3 \% ; P=0.027)$ and at $15+$ years was 2.02 (95\% CI: $1.12-3.66 ; P=0.020$ ). There was little difference in $\mathrm{HR}$ and trend after adjusting for further potential confounding variables (results shown in Supplementary Table 2; distribution of adjustment variables in Supplementary Tables 3 and 4), and hence the following results adjust only for menopausal and attained age. Risk was not significantly increased for past MHT use overall or by type of MHT preparation (Table 2), or oestrogen receptor status (Table 3), or morphological type (Supplementary Table 5), nor did the HR in past users differ by duration of past use $(<5$ years $v s$ $5+$ years: $P_{\text {heterogeneity }}=0.093$ ).
Analysed by type of MHT preparation (Table 2), for oestrogenonly preparations (median duration of current use 6.6 years) breast cancer risk was not significantly increased with current use $(\mathrm{HR}=1.00 ; 95 \% \mathrm{CI}: 0.66-1.54 ; P=0.99)$ and there was a nonsignificant increase in HR per year of use $(4.2 \%$ per year of use; $95 \%$ CI: -1.8 to $10.5 \%$; $P=0.17$ ). For combined oestrogen plus progestogen preparations (median duration of current use 5.4 years) there was a significantly increased risk with current use compared with never use $(\mathrm{HR}=2.74 ; 95 \%$ CI: 2.05-3.65; $P<0.001$ ), and $\mathrm{HR}$ increased by $5.6 \%$ (95\% CI: $1.2-10.2 \%$; $P=0.011)$ per year of use, reaching $\mathrm{HR}=3.27 \quad(95 \% \mathrm{CI}$ :

Table 2. Relative risk ${ }^{a}$ of (invasive and in situ) post-menopausal breast cancer, by type of MHT preparation, in relation to MHT duration and recency of use, in 39183 women from the Breakthrough Generations Study who were recruited during 2003-2009

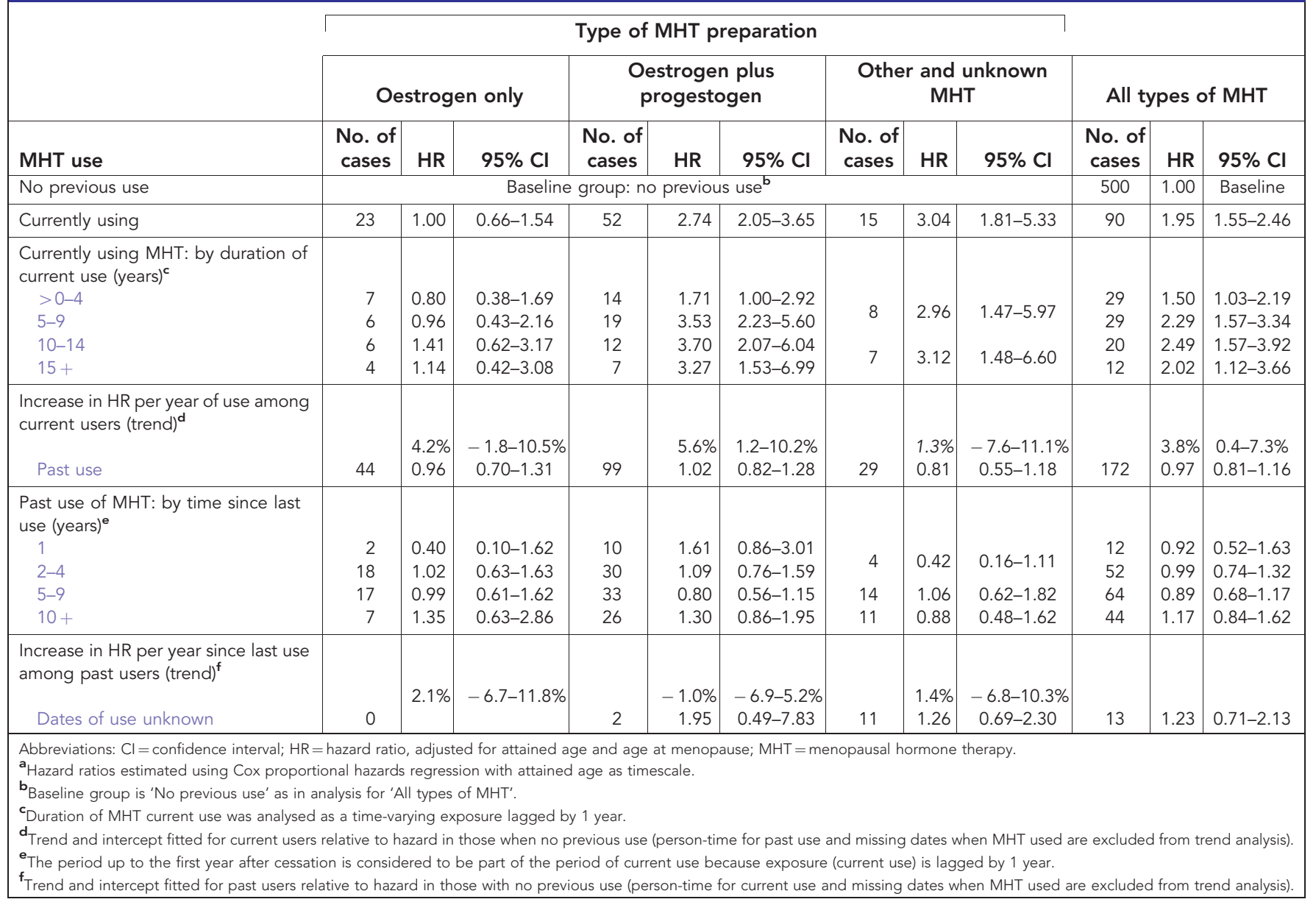

Table 3. Relative risk ${ }^{\mathrm{a}}$ of (invasive and in situ) post-menopausal breast cancer, by oestrogen receptor status, in relation to MHT, in 39183 women from the Breakthrough Generations Study who were recruited during 2003-2009

Breast cancer oestrogen receptor status

\begin{tabular}{|c|c|c|c|c|c|c|c|c|c|}
\hline \multirow[b]{2}{*}{ MHT use } & \multicolumn{3}{|c|}{ Oestrogen receptor positive } & \multicolumn{3}{|c|}{ Oestrogen receptor negative } & \multicolumn{3}{|c|}{ Status unknown } \\
\hline & No. of cases & HR & $95 \% \mathrm{Cl}$ & No. of cases & HR & $95 \% \mathrm{Cl}$ & No. of cases & HR & $95 \% \mathrm{Cl}$ \\
\hline No previous use & 374 & 1.00 & Baseline & 71 & 1.00 & Baseline & 55 & 1.00 & Baseline \\
\hline Currently using oestrogen only MHT & 20 & 1.19 & $0.75-1.88$ & 2 & 0.49 & $0.12-2.03$ & 1 & 0.50 & $0.07-3.66$ \\
\hline Currently using oestrogen plus progestogen MHT & 41 & 2.89 & $2.09-4.00$ & 5 & 1.70 & $0.68-4.24$ & 6 & 3.19 & $1.36-7.44$ \\
\hline Currently using other and unknown MHT & 12 & 3.30 & $1.85-5.87$ & 3 & 3.83 & $1.20-12.28$ & 0 & & \\
\hline Past use & 128 & 0.94 & $0.76-1.16$ & 27 & 1.01 & $0.63-1.62$ & 17 & 1.11 & $0.63-1.97$ \\
\hline Dates of use unknown & 9 & 1.12 & $0.58-2.18$ & 3 & 1.86 & $0.58-5.93$ & 1 & 0.91 & $0.13-6.62$ \\
\hline
\end{tabular}

Abbreviations: $\mathrm{Cl}=$ confidence interval; $\mathrm{HR}=$ hazard ratio, adjusted for attained age and age at menopause; $\mathrm{MHT}=$ menopausal hormone therapy

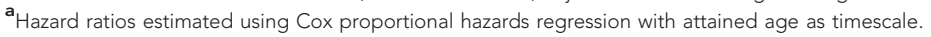


$1.53-6.99 ; P=0.002)$ at $15+$ years of use. As can be seen by the non-overlapping CIs, there was a significant difference between the HRs for breast cancer risk in relation to current oestrogen-only MHT use vs never use compared with current oestrogen plus progestogen use $v s$ never use $\left(P_{\text {heterogeneity }}<0.001\right)$. There was no heterogeneity by time since recruitment for risk of breast cancer in relation to oestrogen-only $\mathrm{MHT}$ use $\left(P_{\text {heterogeneity }}=0.35\right)$ or combined MHT use $\left(P_{\text {heterogeneity }}=0.72\right)$. Without adjustment for menopausal age, the HR for breast cancer and combined oestrogen plus progestogen MHT use was 2.64 (95\% CI: 1.98-3.52; $\mathrm{P}<0.001$ ).

The HR for combined oestrogen plus progestogen preparations was 2.96 (95\% CI: 2.19-3.99; $P<0.001)$ for invasive and 1.46 (95\% CI: $0.53-4.00 ; P=0.47)$ for in situ breast cancer, but the difference between these was not significant $\left(P_{\text {heterogeneity }}=0.18\right)$ and in situ breast cancer only accounted for $14 \%$ of cases (Supplementary Table 6 presents results for invasive breast cancer only). The HRs for combined MHT for ductal $(\mathrm{HR}=2.60$; 95\% CI: $1.86-3.64$; $P<0.001)$ and lobular $(\mathrm{HR}=3.12 ; 95 \% \mathrm{CI}: 1.50-6.51 ; P=0.002)$ breast cancers were both increased but not significantly different to each other $\left(P_{\text {heterogeneity }}=0.60\right.$; Supplementary Table 5$)$. The HR for oestrogen receptor-positive breast cancer was 2.89 (95\% CI: $2.09-4.00 ; P<0.001)$ and was not significantly different to that for oestrogen receptor-negative breast cancer $\left(P_{\text {heterogeneity }}=0.31\right.$; Table 3).

When analysed by type of combined oestrogen plus progestogen MHT, the HR for breast cancer for serial combined preparations $(\mathrm{HR}=2.95 ; 95 \% \mathrm{CI}: 1.92-4.53 ; P<0.001)$ was not significantly different from that for continuous combined preparations $(\mathrm{HR}=2.67 ; 95 \%$ CI: $1.82-3.95 ; P<0.001) \quad\left(P_{\text {heterogeneity }}=0.74\right)$. For other or unspecified types of MHT, of which tibolone use made up $49 \%$, risk compared with never users was significantly increased with current use $(P<0.001)$, but there was no significant trend with duration of use $(P=0.78)$. The HR for breast cancer for current tibolone use was 2.32 (95\% CI: $1.03-5.20 ; P=0.041$ ). Among women with no family history of breast cancer, the HR for current tibolone use was 1.60 (95\% CI: $0.51-4.99 ; P=0.42)$ but this was based on only three cases of breast cancer, and among those with a positive family history of breast cancer the HR was 4.15 (95\% CI: $1.32-13.1 ; P=0.015$ ), but again was based on only three cases of breast cancer, and the difference between the HRs was not significant $(P=0.25)$.

The above analyses update data on MHT use after recruitment using serial questionnaire information and exclude women with uncertain menopausal age (e.g., because of hysterectomy). We next examined the potential biases when these analytic procedures were not done (Table 4). The number of women available for analysis was reduced when using baseline information only because women who become post-menopausal after recruitment were not considered eligible, and the number of women available increased when those with uncertain menopausal age were included, although their follow-up for risk of breast cancer only started at age 58 years (only 13404 women with uncertain menopausal age reached this age during follow-up; descriptive statistics in Supplementary Tables 3 and 4). The excess HR for breast cancer for combined MHT use was 53\% smaller when usage during follow-up was ignored, $13 \%$ smaller when women with uncertain menopausal age were included in analyses, and 59\% smaller for both these analytic approaches combined. If restricted to invasive breast cancer only, the biases were $46 \%, 15 \%$, and $56 \%$ respectively. Table 4 also shows results by duration of use; at each duration there was $\sim 50 \%$ bias when usage during follow-up was ignored.

The interrelation between MHT, BMI, and risk of breast cancer is shown in Table 5 . Risk of breast cancer increased significantly $(P<0.001)$ with greater BMI among women not using MHT and among past users $(P=0.030)$. The risk of breast cancer was increased with current use of combined oestrogen plus progestogen MHT within each category of BMI but there was no significant trend with BMI $(P=0.39)$. The relative increase in risk for combined oestrogen plus progestogen MHT was smaller with greater BMI, for example, for BMI at $+30 \mathrm{~kg} \mathrm{~m}^{-2}$, the HR was $(3.40 / 1.64=) 2.07(95 \% \mathrm{CI}: 0.84-5.10 ; P=0.11)$, BMI at 25 to

Table 4. Relative risk ${ }^{a}$ of (invasive and in situ) post-menopausal breast cancer, by duration of current use of oestrogen plus progestogen MHT, for analyses with and without MHT updated through follow-up and inclusion or exclusion of women with uncertain menopausal age, in women from the Breakthrough Generations Study who were recruited during 2003-2009

\begin{tabular}{|c|c|c|c|c|c|c|c|c|c|c|c|c|c|c|c|}
\hline \multirow[b]{4}{*}{ MHT use } & & & & & & & & & & & & & & & \\
\hline & \multirow{2}{*}{\multicolumn{3}{|c|}{$\begin{array}{c}\text { MHT use updated } \\
\text { through follow-up, } \\
\text { women with } \\
\text { uncertain } \\
\text { menopausal age } \\
\text { excluded }\end{array}$}} & \multicolumn{4}{|c|}{$\begin{array}{l}\text { No updating of MHT } \\
\text { use beyond baseline, } \\
\text { women with uncertain } \\
\text { menopausal } \\
\text { age excluded }\end{array}$} & \multicolumn{4}{|c|}{$\begin{array}{c}\text { MHT use updated } \\
\text { through follow-up, } \\
\text { women with uncertain } \\
\text { menopausal age included }\end{array}$} & \multicolumn{4}{|c|}{$\begin{array}{l}\text { No updating of MHT use } \\
\text { beyond baseline, } \\
\text { women with uncertain } \\
\text { menopausal } \\
\text { age included }\end{array}$} \\
\hline & & & & \multicolumn{4}{|c|}{$\begin{array}{c}\text { (Number of } \\
\text { women }=39183 \text { ) }\end{array}$} & \multicolumn{4}{|c|}{$\begin{array}{c}\text { (Number of } \\
\text { women }=52587)^{b}\end{array}$} & \multicolumn{4}{|c|}{$\begin{array}{c}\text { (Number of } \\
\text { women }=43484)^{b, c}\end{array}$} \\
\hline & $\begin{array}{c}\text { No. } \\
\text { of } \\
\text { cases }\end{array}$ & $\mathrm{HR}$ & $95 \% \mathrm{Cl}$ & $\begin{array}{c}\text { No. } \\
\text { of } \\
\text { cases }\end{array}$ & $\mathrm{HR}$ & $95 \% \mathrm{Cl}$ & Bias $^{d}$ & $\begin{array}{c}\text { No. } \\
\text { of } \\
\text { cases }\end{array}$ & HR & $95 \% \mathrm{Cl}$ & Bias $^{d}$ & $\begin{array}{c}\text { No. } \\
\text { of } \\
\text { cases }\end{array}$ & $\mathrm{HR}$ & $95 \% \mathrm{Cl}$ & Bias $^{d}$ \\
\hline No previous use & 500 & 1.00 & Baseline & 525 & 1.00 & Baseline & & 584 & 1.00 & Baseline & & 531 & 1.00 & Baseline & \\
\hline Currently using & 52 & 2.74 & $2.05-3.65$ & 62 & 1.82 & $1.39-2.38$ & $53 \%$ & 73 & 2.51 & $1.96-3.21$ & $13 \%$ & 101 & 1.71 & $1.38-2.13$ & $59 \%$ \\
\hline \multicolumn{16}{|l|}{$\begin{array}{l}\text { Currently using oestrogen plus } \\
\text { progestogen MHT: by duration of } \\
\text { current use (years) }\end{array}$} \\
\hline $1-4$ & 14 & 1.71 & $1.00-2.92$ & 22 & 1.32 & $0.86-2.02$ & $56 \%$ & 15 & 1.62 & $0.97-2.71$ & $13 \%$ & 30 & 1.26 & $0.87-1.82$ & $63 \%$ \\
\hline $5-9$ & 19 & 3.53 & $2.23-5.60$ & 25 & 2.35 & $1.56-3.53$ & $47 \%$ & 26 & 2.91 & & $25 \%$ & 35 & 1.70 & & $72 \%$ \\
\hline $10+$ & 19 & 3.54 & $2.21-5.65$ & 15 & 2.34 & $1.38-3.97$ & $47 \%$ & 32 & 2.97 & $2.07-4.28$ & $22 \%$ & 36 & 2.51 & 1.77-3.55 & $40 \%$ \\
\hline \multicolumn{16}{|c|}{ 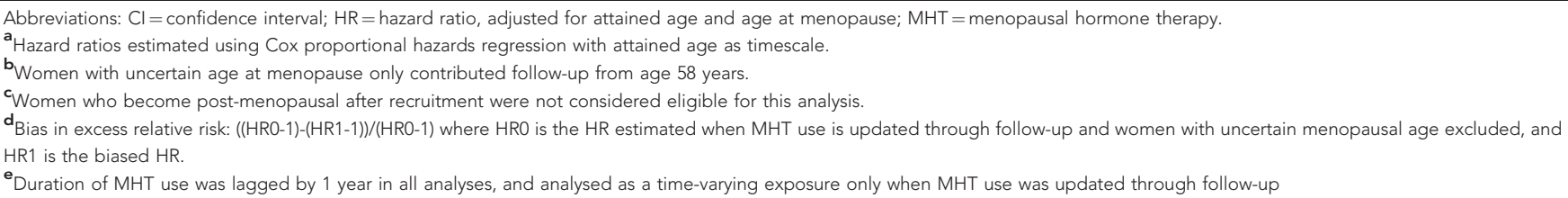 } \\
\hline
\end{tabular}


Table 5. Relative risk ${ }^{a}$ of (invasive and in situ) post-menopausal breast cancer, in relation to MHT, by post-menopausal BMI in $39183^{b}$ women in the Breakthrough Generations Study who were recruited during 2003-2009

\begin{tabular}{|c|c|c|c|c|c|c|c|c|c|c|c|c|c|}
\hline & \multicolumn{9}{|c|}{ Post-menopausal BMI $\left(\mathrm{kg} \mathrm{m}^{-2}\right)$} & \multicolumn{4}{|c|}{ Trend } \\
\hline & \multicolumn{3}{|c|}{$<25$} & \multicolumn{3}{|c|}{$25-<30$} & \multicolumn{3}{|c|}{$30+$} & \multicolumn{4}{|c|}{ (HR per unit increase in $\mathrm{BMI}$ ) } \\
\hline MHT use & $\begin{array}{l}\text { No. of } \\
\text { cases }\end{array}$ & HR & $95 \% \mathrm{Cl}$ & $\begin{array}{l}\text { No. of } \\
\text { cases }\end{array}$ & HR & $95 \% \mathrm{Cl}$ & $\begin{array}{c}\text { No. of } \\
\text { cases }\end{array}$ & HR & $95 \% \mathrm{Cl}$ & HR & $95 \% \mathrm{Cl}$ & $\begin{array}{l}\text { P-value } \\
\text { (trend) }\end{array}$ & $\begin{array}{c}P \text {-value } \\
(\text { heterogeneity) }\end{array}$ \\
\hline No previous use & 203 & 1.00 & Baseline & 188 & 1.36 & $1.12-1.66$ & 100 & 1.64 & $1.29-2.08$ & 1.04 & $1.02-1.06$ & $<0.001$ & - \\
\hline $\begin{array}{l}\text { Currently using oestrogen } \\
\text { only MHT }\end{array}$ & 16 & 1.52 & $0.91-2.54$ & 1 & 0.17 & $0.02-1.21$ & 5 & 2.25 & $0.92-5.52$ & 0.97 & $0.90-1.05$ & 0.51 & 0.17 \\
\hline $\begin{array}{l}\text { Currently using oestrogen } \\
\text { plus progestogen MHT }\end{array}$ & 31 & 3.27 & $2.24-4.78$ & 16 & 3.49 & $2.10-5.82$ & 5 & 3.40 & $1.40-8.26$ & 1.03 & $0.96-1.12$ & 0.39 & 0.79 \\
\hline $\begin{array}{l}\text { Currently using other and } \\
\text { unknown MHT }\end{array}$ & 10 & 4.46 & $2.36-8.43$ & 5 & 3.84 & $1.58-9.32$ & 0 & & & 0.98 & $0.83-1.15$ & 0.78 & 0.41 \\
\hline Past use & 88 & 1.18 & $0.91-1.53$ & 44 & 0.85 & $0.61-1.19$ & 38 & 1.94 & $1.37-2.76$ & 1.04 & $1.00-1.07$ & 0.030 & 0.91 \\
\hline Dates of use unknown & 7 & 1.50 & $0.71-3.19$ & 6 & 2.04 & $0.91-4.61$ & 0 & & & 0.93 & $0.80-1.09$ & 0.39 & 0.18 \\
\hline \multicolumn{14}{|c|}{$\begin{array}{l}\text { Abbreviations: } \mathrm{BMI}=\text { body mass index; } \mathrm{Cl}=\text { confidence interval; } \mathrm{HR}=\text { hazard ratio, adjusted for attained age and age at menopause; } \mathrm{MHT}=\text { menopausal hormone therapy. } \\
\mathrm{a}_{\text {}} \text { Hazard ratios estimated using Cox proportional hazards regression with attained age as timescale. } \\
\mathrm{b}_{\mathrm{A}} \text { total of } 1041 \text { women }(2.7 \%) \text { were excluded from analysis because BMI was not known. } \\
\mathrm{c}_{\text {Trend compared with the trend for no previous use. }}\end{array}$} \\
\hline
\end{tabular}

$<30 \mathrm{~kg} \mathrm{~m}^{-2}$ the HR was $(3.49 / 1.36=) 2.56(95 \% \mathrm{CI}: 1.53-4.27)$, and for BMI $<25 \mathrm{~kg} \mathrm{~m}^{-2}$ it was 3.27 (95\% CI: $2.24-4.78$; $P<0.001$ ), although the CIs overlapped and the trend with BMI was not significantly different to the trend among never users of MHT $\left(P_{\text {heterogeneity }}=0.79\right)$.

\section{DISCUSSION}

In our cohort, the risk of post-menopausal breast cancer was increased with current use of MHT, as in previous studies (Colditz et al, 1995; Collaborative Group on Hormonal Factors in Breast Cancer, 1997; Stahlberg et al, 2004; Campagnoli et al, 2005; Santen et al, 2010; Bakken et al, 2011; Beral et al, 2011; Salagame et al, 2011; Anderson et al, 2012; Chlebowski and Anderson, 2012), and the increase in risk was larger with combined oestrogen plus progestogen than with oestrogen-only formulations, again as seen before (Colditz et al, 1995; Olsson et al, 2003; Stahlberg et al, 2004; Campagnoli et al, 2005; Bakken et al, 2011; Beral et al, 2011; Chlebowski and Anderson, 2012; Roman et al, 2016). In particular, our relative risk estimates for current use of combined MHT are compatible with the results from epidemiological studies that have updated MHT use by questionnaire (Chen et al, 2004; Calle et al, 2009; Beral et al, 2011; Fournier et al, 2014) or record linkage (Roman et al, 2016). Relative risk increased with greater duration of current combined MHT use, to 3.27 at $15+$ years of use, and these long-term risks were larger than those previously reported (Li et al, 2003; Brinton et al, 2008; Saxena et al, 2010), although there is considerable overlap in the CIs around these estimates.

We also found the association between risk of breast cancer and combined MHT use was compatible with previous publications that have shown attenuation of MHT-associated breast cancer risks in women with high BMI relative to non-users of MHT with similar BMI (Beral et al, 2011; Ritte et al, 2012); consequently, care is needed when comparing results between studies if they differ in BMI profile. Our results, however, should be comparable with other large epidemiological studies in this respect as the average post-menopausal BMI of women in our study $\left(25.7 \mathrm{~kg} \mathrm{~m}^{-2}\right)$ was similar to that in the Million Women Study $\left(26.2 \mathrm{~kg} \mathrm{~m}^{-2}\right.$; Beral et al, 2011), the European Prospective Investigation into Cancer and Nutrition $\left(24.8 \mathrm{~kg} \mathrm{~m}^{-2}\right.$; Ritte et al, 2012), and the Nurses' Health Study $\left(24.9 \mathrm{~kg} \mathrm{~m}^{-2}\right.$; Kotsopoulos et al, 2010), although notably lower than in the Women's Health Initiative trial (28.5 $\mathrm{kg} \mathrm{m}^{-2}$; Rossouw et al, 2002). However, our results for women with BMI $25-<30 \mathrm{~kg} \mathrm{~m}^{-2}(\mathrm{HR}=2.56$; 95\% CI: $1.53-4.27)$ can be compared with the Women's Health Initiative trial and observational study results for women who began combined MHT use within 5 years of menopause $(\mathrm{HR}=1.64 ; 95 \% \mathrm{CI}: 1.00-2.68)$ (Prentice et al, 2008); our HR is larger but the CIs from both studies overlap.

We included invasive and in situ breast cancer as the analysis end point, similar to the Million Women Study (Beral et al, 2011), although when we re-analysed using only invasive breast cancer as the end point we saw modestly larger relative risks, but this did not materially change our conclusions (for direct comparability with studies that only include invasive breast cancer these results are available in Supplementary Table 6).

Previous studies have found greater risks for oestrogen receptorpositive than -negative breast cancer (Li et al, 2003; Chen et al, 2004; Fournier et al, 2008), and we also saw the same for combined MHT use, although the difference in risks in our study was not statistically significant perhaps because there were few current users of MHT who developed oestrogen receptor-negative breast cancer, and with 775 cases of breast cancer and only 52 cases currently using combined MHT the study lacked power to detect such statistical interactions. Our information on oestrogen receptor status also has some limitations because it came from cancer registration reports and the cutoffs used to define positive/negative were not standardised beyond that used in routine practice. We did not find overall increased risks stronger with combined continuous regimens than sequential ones, consistent with studies from the United Kingdom and the United States (Beral and Million Women Study Collaborators, 2003; Li et al, 2003; Campagnoli et al, 2005; Brinton et al, 2008; Opatrny et al, 2008), although studies from northern Europe have tended to show higher rates for continuous relative to sequential regimens (Olsson et al, 2003; Stahlberg et al, 2004; Campagnoli et al, 2005; Bakken et al, 2011; Roman et al, 2016) and the disparity may be because of differences in progestogen monthly dose (Bakken et al, 2004; Stahlberg et al, 2004; Campagnoli et al, 2005; Roman et al, 2016). The most frequently used serial regimens in our study were Prempak-C (conjugated oestrogen, $625 \mu \mathrm{g}$ and $1.25 \mathrm{mg}$; norgestrel, $150 \mu \mathrm{g}$ ), Elleste Duet (estradiol, 1 and $2 \mathrm{mg}$; norethisterone, $1 \mathrm{mg}$ ), and Climagest (Estradiol, $2 \mathrm{mg}$; norethisterone, $1 \mathrm{mg}$ ), and the most frequently used continuous regimens were Premique (conjugated oestrogen, $625 \mu \mathrm{g}$; medroxyprogesterone acetate, $5 \mathrm{mg}$ ), Kilovance (estradiol, $1 \mathrm{mg}$; norethisterone, $500 \mu \mathrm{g}$ ), and Kilofem (estradiol, $2 \mathrm{mg}$; norethisterone, $1 \mathrm{mg}$ ). 
We found significantly increased risk with other or unspecified types of MHT. There was, however, no significant trend with duration of use in this group, perhaps because the increased risk may be a characteristic of women who take these other types of preparation rather than an effect of the preparation itself. The most common type of MHT in this group was tibolone, a selective tissue oestrogenic activity regulator, and evidence suggests that in the United Kingdom it is preferentially prescribed to women at increased risk of breast cancer (Velthuis-Te Wierik et al, 2007).

Our MHT exposure information was gained at recruitment and from follow-up questionnaire 6 years later. As 96\% of women completed this follow-up it seems unlikely that misclassification of exposure in the remaining $4 \%$ would have materially influenced our results. Some of our MHT usage was collected after diagnosis of breast cancer and this has potential to introduce recall bias. If women with breast cancer were more motivated to recall past exposures we may expect to have seen increased risks for oestrogen-only MHT and combined MHT separately but the HR for oestrogen-only MHT use was not increased. However, given the attention that the combined MHT has received in the lay press, women with breast cancer may preferentially recall combined MHT use. However, we note that only 10 out of the 52 women diagnosed with breast cancer, and who were current users of combined MHT, first started MHT use after recruitment to the study and the other 42 reported current use at recruitment, before their breast cancer diagnosis. It therefore seems unlikely that our results are appreciably affected by recall bias. Follow-up for vital and breast cancer status was obtained for $99 \%$ of participants and confirmation of reported breast cancers for $98 \%$, and hence there was little scope for biases from unascertained mortality or exits, or erroneous reporting of breast cancer. A large proportion of women were excluded from our main analysis because their age at menopause was uncertain or unknown, usually because they started MHT or had hysterectomy without oophorectomy, before cessation of menstrual bleeding. A benefit gained by their exclusion is that our analysis was not diluted by the inclusion of possibly misclassified pre-menopausal women. Furthermore, the exclusion of women with unknown age at menopause does not produce biased results in prospective studies because these women could legitimately not have been recruited to a cohort if they were deemed ineligible by protocol; however, as a consequence our results may be less generalisable to all post-menopausal women. This lack of generalisability also affects other studies that have considered it inappropriate to include these women in their main analyses of MHT and breast cancer risk (Collaborative Group on Hormonal Factors in Breast Cancer, 1997; Pike et al, 1998; Ross et al, 2000; Rosenberg et al, 2006).

There are potential biases in cohort studies that only collect information on history of MHT use up to the time of recruitment (e.g., with no follow-up exposure data) that can seriously misclassify actual use (Van Leeuwen and Rookus, 2003; Lee et al, 2005). Magnitude of effect in randomised controlled trials may also suffer from bias because of misclassification of exposure if adherence to treatment is not complete. For example, in the Women's Health Initiative trial of combined MHT, $42 \%$ of women in the active treatment arm discontinued MHT, and $10.7 \%$ of women in the placebo arm started MHT, at some point during the active intervention (Rossouw et al, 2002).

By using information from follow-up questionnaires we were able to update MHT status and duration right up to the breast cancer diagnosis or censoring date, and hence avoid the misclassification that would occur if only baseline questionnaire information was available. Without such follow-up information (i.e., as in many published cohorts (Beral and Million Women Study Collaborators, 2003; Bakken et al, 2004, 2011; Stahlberg et al, 2004; Brinton et al, 2008; Saxena et al, 2010; Nyante et al, 2013)) we found that the excess breast cancer risk for combined MHT would be underestimated by $\sim 53 \%$. The Women's Health Initiative randomised clinical trial saw a similar degree of underestimation in risk of breast cancer for oestrogen plus progestogen treatment relative to placebo when comparing an analysis making allowance for nonadherence to MHT with an intention-to-treat analysis (49\% increased risk of breast cancer $v s$ a $24 \%$ increased risk; i.e., $51 \%$ reduction in excess relative risk) (Chlebowski and Anderson, 2012).

Biases may also occur if analyses included women with simple hysterectomy before menopause (i.e., without oophorectomy) or who started MHT before cessation of menstrual bleeding (Collaborative Group on Hormonal Factors in Breast Cancer, 1997; Pike et al, 1998; Rockhill et al, 2000; Simpson et al, 2007), as most published cohort and case-control studies have done (Colditz et al, 1995; Magnusson et al, 1999; Li et al, 2000; Schairer et al, 2000; Daling et al, 2002; Newcomb et al, 2002; Beral and Million Women Study Collaborators, 2003; Li et al, 2003; Bakken et al, 2004, 2011; Chen et al, 2004, 2006; Stahlberg et al, 2004; Fournier et al, 2005; Brinton et al, 2008; Saxena et al, 2010; Beral et al, 2011; Calvocoressi et al, 2012; Ritte et al, 2012; Cordina-Duverger et al, 2013; Fournier et al, 2014; Thorbjarnardottir et al, 2014; Roman et al, 2016). We found that the consequent underestimation of the excess HR for combined MHT use, because of not adjusting adequately for menopausal age, was $\sim 13 \%$. However, women with simple hysterectomy, or those who started MHT before cessation of menstrual bleeding, may be different to women with known age at menopause, and this could be responsible for some or all of the bias.

For the combination of both the above types of bias we found that excess breast cancer risks would be underestimated by $59 \%$. However, the uncertainty around this estimate is large (we estimate 35-83\%), and furthermore study-specific characteristics (e.g., when study was conducted, duration of follow-up, etc.) are also likely to affect the size of bias that might be seen in other studies. The misclassification of current use of MHT may be less important in older studies conducted before results were published from the Women's Health Initiative trial (Rossouw et al, 2002) and Million Women Study (Beral and Million Women Study Collaborators, 2003) as following these reports women stopped using MHT in large numbers (Chlebowski and Anderson, 2012; Ameye et al, 2014). However, current advice suggests women should use MHT for the shortest possible time (Stuenkel et al, 2015), and thus observational studies conducted post 2002/2003 should be cautious about assuming MHT use at baseline will continue for the duration of the study.

A number of cohort studies have reported relative risks for breast cancer of $\sim 2.0$ to 2.5 for $\geqslant 10$ years of combined MHT use (Beral and Million Women Study Collaborators, 2003; Brinton et al, 2008; Santen et al, 2010; Saxena et al, 2010; Bakken et al, 2011), but this is presumably an underestimate because all of these studies did not update MHT use through follow-up and included in analyses women with uncertain menopausal age. If correction is made for the bias this induces, we estimate the relative risk would be in the range 2.7 to 3.5 , similar to the 3.5 we observed for $10+$ years of use. However, at shorter durations of use too we saw appreciable bias and underestimation of the relative risk for combined MHT use.

In conclusion, our results show that risk of breast cancer increases with duration of use of combined MHT up to $\geqslant 15$ years, and relative risks in most of the published literature are likely to be substantially underestimated because of lack of updating MHT status through follow-up in cohort studies and inclusion of women with inferred menopausal age in cohort or case-control analyses. These results provide further information to allow women to make informed decisions about the potential risks and benefits of MHT use. 


\section{ACKNOWLEDGEMENTS}

We thank Breast Cancer Now and the Institute of Cancer Research for support and funding of the Breakthrough Generations Study, and the study participants, study staff, and the doctors, nurses, and other health-care providers and health information sources who have contributed to the study. We acknowledge NHS funding to the Royal Marsden/ICR NIHR Biomedical Research Centre.

\section{CONFLICT OF INTEREST}

The authors declare no conflict of interest.

\section{REFERENCES}

Ameye L, Antoine C, Paesmans M, de Azambuja E, Rozenberg S (2014) Menopausal hormone therapy use in 17 European countries during the last decade. Maturitas 79(3): 287-291.

Anderson GL, Chlebowski RT, Aragaki AK, Kuller LH, Manson JE, Gass M, Bluhm E, Connelly S, Hubbell FA, Lane D, Martin L, Ockene J, Rohan T, Schenken R, Wactawski-Wende J (2012) Conjugated equine oestrogen and breast cancer incidence and mortality in postmenopausal women with hysterectomy: extended follow-up of the Women's Health Initiative randomised placebo-controlled trial. Lancet Oncol 13(5): 476-486.

Antoine C, Ameye L, Paesmans M, de Azambuja E, Rozenberg S (2016) Menopausal hormone therapy use in relation to breast cancer incidence in 11 European countries. Maturitas 84: 81-88.

Bakken K, Alsaker E, Eggen AE, Lund E (2004) Hormone replacement therapy and incidence of hormone-dependent cancers in the Norwegian Women and Cancer study. Int J Cancer 112(1): 130-134.

Bakken K, Fournier A, Lund E, Waaseth M, Dumeaux V, Clavel-Chapelon F, Fabre A, Hemon B, Rinaldi S, Chajes V, Slimani N, Allen NE, Reeves GK, Bingham S, Khaw KT, Olsen A, Tjonneland A, Rodriguez L, Sanchez MJ, Etxezarreta PA, Ardanaz E, Tormo MJ, Peeters PH, van Gils CH, Steffen A, Schulz M, Chang-Claude J, Kaaks R, Tumino R, Gallo V, Norat T, Riboli E, Panico S, Masala G, Gonzalez CA, Berrino F (2011) Menopausal hormone therapy and breast cancer risk: impact of different treatments. The European Prospective Investigation into Cancer and Nutrition. Int J Cancer 128(1): 144-156.

Beral V. Million Women Study Collaborators (2003) Breast cancer and hormone-replacement therapy in the Million Women Study. Lancet 362(9382): 419-427.

Beral V, Reeves G, Bull D, Green J. Million Women Study Collaborators (2011) Breast cancer risk in relation to the interval between menopause and starting hormone therapy. J Natl Cancer Inst 103(4): 296-305.

Brinton LA, Richesson D, Leitzmann MF, Gierach GL, Schatzkin A, Mouw T, Hollenbeck AR, Lacey Jr JV (2008) Menopausal hormone therapy and breast cancer risk in the NIH-AARP Diet and Health Study Cohort. Cancer Epidemiol Biomarkers Prev 17(11): 3150-3160.

Calle EE, Feigelson HS, Hildebrand JS, Teras LR, Thun MJ, Rodriguez C (2009) Postmenopausal hormone use and breast cancer associations differ by hormone regimen and histologic subtype. Cancer 115(5): 936-945.

Calvocoressi L, Stowe MH, Carter D, Claus EB (2012) Postmenopausal hormone therapy and ductal carcinoma in situ: a population-based case-control study. Cancer Epidemiol 36(2): 161-168.

Campagnoli C, Clavel-Chapelon F, Kaaks R, Peris C, Berrino F (2005) Progestins and progesterone in hormone replacement therapy and the risk of breast cancer. J Steroid Biochem Mol Biol 96(2): 95-108.

Chen WY, Hankinson SE, Schnitt SJ, Rosner BA, Holmes MD, Colditz GA (2004) Association of hormone replacement therapy to estrogen and progesterone receptor status in invasive breast carcinoma. Cancer 101(7): 1490-1500.

Chen WY, Manson JE, Hankinson SE, Rosner B, Holmes MD, Willett WC, Colditz GA (2006) Unopposed estrogen therapy and the risk of invasive breast cancer. Arch Intern Med 166(9): 1027-1032.

Chlebowski RT, Anderson GL (2012) Changing concepts: menopausal hormone therapy and breast cancer. J Natl Cancer Inst 104(7): 517-527.

Colditz GA, Hankinson SE, Hunter DJ, Willett WC, Manson JE, Stampfer MJ, Hennekens C, Rosner B, Speizer FE (1995) The use of estrogens and progestins and the risk of breast cancer in postmenopausal women. $N$ Engl J Med 332(24): 1589-1593.

Collaborative Group on Hormonal Factors in Breast Cancer (1997) Breast cancer and hormone replacement therapy: collaborative reanalysis of data from 51 epidemiological studies of 52,705 women with breast cancer and 108,411 women without breast cancer. Collaborative Group on Hormonal Factors in Breast Cancer. Lancet 350(9084): 1047-1059.

Cordina-Duverger E, Truong T, Anger A, Sanchez M, Arveux P, Kerbrat P, Guenel P (2013) Risk of breast cancer by type of menopausal hormone therapy: a case-control study among post-menopausal women in France. PLoS One 8(11): e78016.

Cox DR (1972) Regression models and life-tables. J R Stat Soc B 34(2): 187-220.

Daling JR, Malone KE, Doody DR, Voigt LF, Bernstein L, Coates RJ, Marchbanks PA, Norman SA, Weiss LK, Ursin G, Berlin JA, Burkman RT, Deapen D, Folger SG, McDonald JA, Simon MS, Strom BL, Wingo PA, Spirtas R (2002) Relation of regimens of combined hormone replacement therapy to lobular, ductal, and other histologic types of breast carcinoma. Cancer 95(12): 2455-2464.

Fournier A, Berrino F, Riboli E, Avenel V, Clavel-Chapelon F (2005) Breast cancer risk in relation to different types of hormone replacement therapy in the E3N-EPIC cohort. Int J Cancer 114(3): 448-454.

Fournier A, Fabre A, Mesrine S, Boutron-Ruault MC, Berrino F, Clavel-Chapelon F (2008) Use of different postmenopausal hormone therapies and risk of histology- and hormone receptor-defined invasive breast cancer. J Clin Oncol 26(8): 1260-1268.

Fournier A, Mesrine S, Dossus L, Boutron-Ruault MC, Clavel-Chapelon F, Chabbert-Buffet N (2014) Risk of breast cancer after stopping menopausal hormone therapy in the E3N cohort. Breast Cancer Res Treat 145(2): 535-543.

Greiser CM, Greiser EM, Doren M (2005) Menopausal hormone therapy and risk of breast cancer: a meta-analysis of epidemiological studies and randomized controlled trials. Hum Reprod Update 11(6): 561-573.

Kotsopoulos J, Chen WY, Gates MA, Tworoger SS, Hankinson SE, Rosner BA (2010) Risk factors for ductal and lobular breast cancer: results from the nurses' health study. Breast Cancer Res 12(6): R106.

Lee SA, Ross RK, Pike MC (2005) An overview of menopausal oestrogenprogestin hormone therapy and breast cancer risk. Br J Cancer 92(11): 2049-2058.

Li CI, Malone KE, Porter PL, Weiss NS, Tang MT, Cushing-Haugen KL, Daling JR (2003) Relationship between long durations and different regimens of hormone therapy and risk of breast cancer. JAMA 289(24): 3254-3263.

Li CI, Weiss NS, Stanford JL, Daling JR (2000) Hormone replacement therapy in relation to risk of lobular and ductal breast carcinoma in middle-aged women. Cancer 88(11): 2570-2577.

Lunn M, McNeil D (1995) Applying Cox regression to competing risks. Biometrics 51(2): 524-532.

Magnusson C, Baron JA, Correia N, Bergstrom R, Adami HO, Persson I (1999) Breast-cancer risk following long-term oestrogen- and oestrogen-progestin-replacement therapy. Int J Cancer 81(3): 339-344.

Medicines and Healthcare Products Regulatory Agency UK (2007) Hormone-replacement therapy: safety update - UK Public Assessment Report.

Newcomb PA, Titus-Ernstoff L, Egan KM, Trentham-Dietz A, Baron JA, Storer BE, Willett WC, Stampfer MJ (2002) Postmenopausal estrogen and progestin use in relation to breast cancer risk. Cancer Epidemiol Biomarkers Prev 11(7): 593-600.

Nyante SJ, Dallal CM, Gierach GL, Park Y, Hollenbeck AR, Brinton LA (2013) Risk factors for specific histopathological types of postmenopausal breast cancer in the NIH-AARP Diet and Health Study. Am J Epidemiol 178(3): 359-371.

Olsson HL, Ingvar C, Bladstrom A (2003) Hormone replacement therapy containing progestins and given continuously increases breast carcinoma risk in Sweden. Cancer 97(6): 1387-1392.

Opatrny L, Dell'Aniello S, Assouline S, Suissa S (2008) Hormone replacement therapy use and variations in the risk of breast cancer. BJOG 115(2): 169-175.

Pike MC, Ross RK, Spicer DV (1998) Problems involved in including women with simple hysterectomy in epidemiologic studies measuring the effects of hormone replacement therapy on breast cancer risk. Am J Epidemiol 147(8): 718-721.

Prentice RL, Chlebowski RT, Stefanick ML, Manson JE, Pettinger M, Hendrix SL, Hubbell FA, Kooperberg C, Kuller LH, Lane DS, 
McTiernan A, Jo O'Sullivan M, Rossouw JE, Anderson GL (2008) Estrogen plus progestin therapy and breast cancer in recently postmenopausal women. Am J Epidemiol 167(10): 1207-1216.

Ritte R, Lukanova A, Berrino F, Dossus L, Tjonneland A, Olsen A, Overvad TF, Overvad K, Clavel-Chapelon F, Fournier A, Fagherazzi G, Rohrmann S, Teucher B, Boeing H, Aleksandrova K, Trichopoulou A, Lagiou P, Trichopoulos D, Palli D, Sieri S, Panico S, Tumino R, Vineis P, Quiros JR, Buckland G, Sanchez MJ, Amiano P, Chirlaque MD, Ardanaz E, Sund M, Lenner P, Bueno-de-Mesquita B, van Gils CH, Peeters PH, Krum-Hansen S, Gram IT, Lund E, Khaw KT, Wareham N, Allen NE, Key TJ, Romieu I, Rinaldi S, Siddiq A, Cox D, Riboli E, Kaaks R (2012) Adiposity, hormone replacement therapy use and breast cancer risk by age and hormone receptor status: a large prospective cohort study. Breast Cancer Res 14(3): R76.

Rockhill B, Colditz GA, Rosner B (2000) Bias in breast cancer analyses due to error in age at menopause. Am J Epidemiol 151(4): 404-408.

Roman M, Sakshaug S, Graff-Iversen S, Vangen S, Weiderpass E, Ursin G, Hofvind S (2016) Postmenopausal hormone therapy and the risk of breast cancer in Norway. Int J Cancer 138(3): 584-593.

Rosenberg LU, Magnusson C, Lindstrom E, Wedren S, Hall P, Dickman PW (2006) Menopausal hormone therapy and other breast cancer risk factors in relation to the risk of different histological subtypes of breast cancer: a case-control study. Breast Cancer Res 8(1): R11.

Ross RK, Paganini-Hill A, Wan PC, Pike MC (2000) Effect of hormone replacement therapy on breast cancer risk: estrogen versus estrogen plus progestin. J Natl Cancer Inst 92(4): 328-332.

Rossouw JE, Anderson GL, Prentice RL, LaCroix AZ, Kooperberg C, Stefanick ML, Jackson RD, Beresford SA, Howard BV, Johnson KC, Kotchen JM, Ockene J. Writing Group for the Women's Health Initiative Investigators (2002) Risks and benefits of estrogen plus progestin in healthy postmenopausal women: principal results From the Women's Health Initiative randomized controlled trial. JAMA 288(3): 321-333.

Salagame U, Canfell K, Banks E (2011) An epidemiological overview of the relationship between hormone replacement therapy and breast cancer. Expert Rev Endocrinol Metab 6(3): 397-409.

Santen RJ, Allred DC, Ardoin SP, Archer DF, Boyd N, Braunstein GD, Burger HG, Colditz GA, Davis SR, Gambacciani M, Gower BA, Henderson VW, Jarjour WN, Karas RH, Kleerekoper M, Lobo RA, Manson JE, Marsden J, Martin KA, Martin L, Pinkerton JV, Rubinow DR, Teede H, Thiboutot DM, Utian WH, Endocrine S (2010) Postmenopausal hormone therapy: an Endocrine Society scientific statement. J Clin Endocrinol Metab 95(7 Suppl 1): s1-s66.

Saxena T, Lee E, Henderson KD, Clarke CA, West D, Marshall SF, Deapen D, Bernstein L, Ursin G (2010) Menopausal hormone therapy and subsequent risk of specific invasive breast cancer subtypes in the California Teachers Study. Cancer Epidemiol Biomarkers Prev 19(9): 2366-2378.

Schairer C, Lubin J, Troisi R, Sturgeon S, Brinton L, Hoover R (2000) Menopausal estrogen and estrogen-progestin replacement therapy and breast cancer risk. JAMA 283(4): 485-491.

Simpson JA, English DR, MacInnis RJ, Gertig DM, Hopper JL, Giles GG (2007) A comparison of different methods for including 'age at menopause' in analyses of the association between hormone replacement therapy use and breast cancer. J Fam Plan Reprod H 33(1): $11-16$.

Stahlberg C, Pedersen AT, Lynge E, Andersen ZJ, Keiding N, Hundrup YA, Obel EB, Ottesen B (2004) Increased risk of breast cancer following different regimens of hormone replacement therapy frequently used in Europe. Int J Cancer 109(5): 721-727.

StataCorp (2015) Stata Statistical Software: Release 14StataCorp LP: College Station, TX.

Stuenkel CA, Davis SR, Gompel A, Lumsden MA, Murad MH, Pinkerton JV, Santen RJ (2015) Treatment of symptoms of the menopause: an Endocrine Society Clinical Practice Guideline. J Clin Endocrinol Metab 100(11): 3975-4011.

Swerdlow AJ, Jones ME, Schoemaker MJ, Hemming J, Thomas D, Williamson J, Ashworth A (2011) The Breakthrough Generations Study: design of a long-term UK cohort study to investigate breast cancer aetiology. Br J Cancer 105(7): 911-917.

Thorbjarnardottir T, Olafsdottir EJ, Valdimarsdottir UA, Olafsson O, Tryggvadottir L (2014) Oral contraceptives, hormone replacement therapy and breast cancer risk: a cohort study of 16928 women 48 years and older. Acta Oncol 53(6): 752-758.

Van Leeuwen FE, Rookus MA (2003) Breast cancer and hormonereplacement therapy: the Million Women Study. Lancet 362(9392): 1330 1330-1331; author reply 1330-1331.

Velthuis-Te Wierik EJ, Hendricks PT, Martinez C (2007) Preferential prescribing of tibolone and combined estrogen plus progestogen therapy in postmenopausal women. Menopause 14(3): 518-527.

Vickers MR, Martin J, Meade TW. WISDOM study team (2007) The Women's international study of long-duration oestrogen after menopause (WISDOM): a randomised controlled trial. BMC Womens Health 7: 2 .

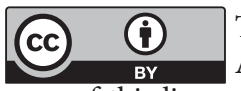
This work is licensed under the Creative Commons Attribution 4.0 International License. To view a copy of this license, visit http://creativecommons.org/licenses/by/4.0/

Supplementary Information accompanies this paper on British Journal of Cancer website (http://www.nature.com/bjc) 